\title{
Factors Affecting Consumer Resistance to Innovation Diffusion of E-Cigarettes
}

\author{
Nastasje Johnson, Marike Venter \\ University of the Witwatersrand, South Africa \\ Nastasje.johnson@gmail.com, Marike.venter@wits.ac.za
}

\begin{abstract}
With increasing concern over the harmful effects of smoking tobacco cigarettes, the use of alternate smoking devices such as the e-cigarette has grown. Although gaining popularity globally, consumer resistance has slowed the diffusion of e-cigarettes in emerging markets, especially in South Africa. The aim of this paper is to explore how consumer resistance affects the diffusion of e-cigarettes among university students in Johannesburg. The study predicts consumer resistance through exploring relative advantage, compatibility, complexity, trialability, observability, and perceived risk. By means of a quantitative methodology, selfadministered questionnaires were completed by 400 students from the University of the Witwatersrand. The data analysis was conducted using SPSS 22 and AMOS for structural equation modelling, which yielded results indicative of support for three of the six hypotheses proposed. This indicates that although marketers should apply relative advantage $(\beta=0.03)$ and complexity $(\beta=0.16)$ to marketing strategies, the focus should be on perceived risk $(\beta=0.88)$ in order to increase the diffusion of e-cigarettes in the youth market. The results further provide marketing practitioners with a better understanding on how to limit consumer resistance and how to improve product diffusion of e-cigarettes. This study contributes to existing literature on innovation diffusion, and contextually to buying behaviour among the youth in South Africa. By gaining insight into this, marketers will positively influence behavioural change among smokers and so contribute to the reduction in smoking-related deaths.
\end{abstract}

Keywords: e-Cigarette, Consumer Resistance, Diffusion, Adoption, Innovation

\section{Introduction}

Globally, it is estimated that six million people die prematurely from smoking each year, and of that number, 600000 are the result of exposure to second hand smoke (World Health Organisation, 2015). Due to this concern, there is need for safer smoking alternatives (Polosa, Caponnetto, Morjaria, Papale, Campagna, \& Russo, 2011). As a result, the e-cigarette was introduced (Odum, O'Dell, \& Schepers, 2012). The e-cigarette, also known as an electronic cigarette, is a hand-held, battery-powered device that allows the user to inhale recreationally vaporised nicotine (Barbeau, Burda \& Siegel, 2013; Goniewicz, Lingas \& Hajek, 2013; Schripp, Markewitz, Udhe \& Salthammer, 2013; Sutfin, McCoy, Morrell, Hoeppner \& Wolfson, 2013). Although researchers have identified the e-cigarette as a potentially successful smoking reduction device that aids in smoking cessation, it is perceived as a controversial product for two reasons: firstly, users still inhale the addictive substance, nicotine and, secondly, the health implications of any bi-products created during the process of heating e-liquid into vapour are still unconfirmed (Borland, 2011; Goniewicz, Knysak, Kosmider, Sobczak, Kurek, Prokopowiz, Jablonska-Czapla, Rosik-Dulewska, Havel, Jacob \& Benowitz, 2013; Health New Zealand, 2009; Heavner, Dunworth, Bergen, Nissen \& Phillips, 2009). Besides these concerns surrounding the use of e-cigarettes, there remains a level of consumer resistance towards adopting this product as a healthier, smoking alternative.

With consumer resistance affecting innovation diffusion, there are underlying economic and social consequences, such as the high rate of new product failures faced by many corporations (Claudy, 2011). These failures equate not only to economic losses of profitability but also to social boycotts that insinuate brand incompetence and lead to consumers switching to competitor brands (Abzakh, Ling, and Alkilani, 2013; Dwivedi, 2005). However, consumer resistance is necessary in creating market value by co-developing new market ideas and altering the market, which ultimately affects the rate of adoption (Cova \& Dalli, 2008; Denegri-Knott, Zwick \& Schroeder, 2006). Understanding the effects of consumer resistance to innovation diffusion can then avoid these negative consequences (Gourville, 2006). Although a number of studies have 
been conducted on this topic (Haghirian, Madlberger \& Inoue, 2008; MacVaugh \& Schiavone, 2010; Abzakh et al., 2013; Moraes, Szmigin \& Carrigan, 2008), a lack of research on the factors influencing e-cigarette resistance remains. The present study aims to fill this gap in literature by investigating the factors that cause consumer resistance to e-cigarette adoption (Claudy, O’Driscoll, Garcia \& Mullen, 2010). By means of a proposed conceptual model grounded in Dwivedi's (2005) model of innovation diffusion, the predictor variables for the present study are relative advantage, compatibility, complexity, trialability, observability and perceived risk, while the outcome variable is consumer resistance. This study provides marketing practitioners with a better understanding of factors that influence e-cigarette resistance among South African youth. Consequently, it provides insight into how practitioners can better position the e-cigarette among the youth in Johannesburg to encourage non-smoking behaviour. Furthermore, it adds to existing literature on innovation diffusion and resistance.

\section{Literature Review}

The Diffusion of Innovations Model: The Innovations Diffusion Model and consumer resistance has been of significant interest to researchers and as a result, a considerate amount of research on this topic has been conducted, as presented in Table 1.

Table 1: Previous Research on Innovation Diffusion and Consumer Resistance

\begin{tabular}{ll}
\hline Construct & Topical Previous Research \\
\hline Relative Advantage & Al-Jabri \& Sohail, 2012; Claudy, 2011; Claudy et al., 2010; Chinman et al., \\
& 2008; Demoulin \& Zidda, 2009; Dwivedi, 2005; Lichtenstein \& \\
& Williamson, 2006; Schwarz \& Ernst, 2008. \\
Compatibility & Claudy, 2011; Kleijnen et al., 2009; Lichtenstein \& Williamson, 2006 \\
Complexity & Claudy, 2011; Claudy et al., 2010; Demoulin \& Zidda, 2009; Korhonen \& \\
& Kaarela, 2011; MacVaugh \& Schiavone, 2010. \\
Trialability & Chinman et al., 2008; Claudy et al., 2010; Demoulin \& Zidda, 2009; \\
& Lichtenstein \& Williamson, 2006; Schwarz \& Ernst, 2008. \\
Observability & Fetscherin \& Lattemann's, 2008; Kleijnen et al., 2009; Lichtenstein \& \\
& Williamson, 2006. \\
Perceived Risk & Abzakh et al., 2013; Dwivedi, 2005; Kleijnen et al., 2009; Talke et al., \\
& 2009; Schwarz \& Ernst, 2008; Talke et al., 2009. \\
Consumer Resistance & Abzakh et al., 2013; Cova \& Dalli, 2008; Galvagno, 2010; Kleijnen et al., \\
& 2009; Moraes et al., 2008. \\
\hline
\end{tabular}

The Diffusion of Innovations Model relates adoption and behaviour to innovations by explaining how the process occurs over a certain period of time (Haghirian et al., 2008; Kumar, Kukerji, Butt \& Persaud, 2007). Marketers find this model useful as it critically describes the adoption or non-adoption of innovations by consumers (MacVaugh \& Schiavone, 2010). Within this model, there are five constructs that influence innovation diffusion, namely, relative advantage, compatibility, complexity, trialability, and observability (Dwivedi, 2005; Kleijnen, Lee \& Wetzels, 2009). However, in later studies conducted by Rogers (2003),it was found that perceived risk is also an influential construct in innovation diffusion, therefore it was added as a construct to the model (Dwivedi, 2005).

Figure 1: The Diffusion of Innovations Model

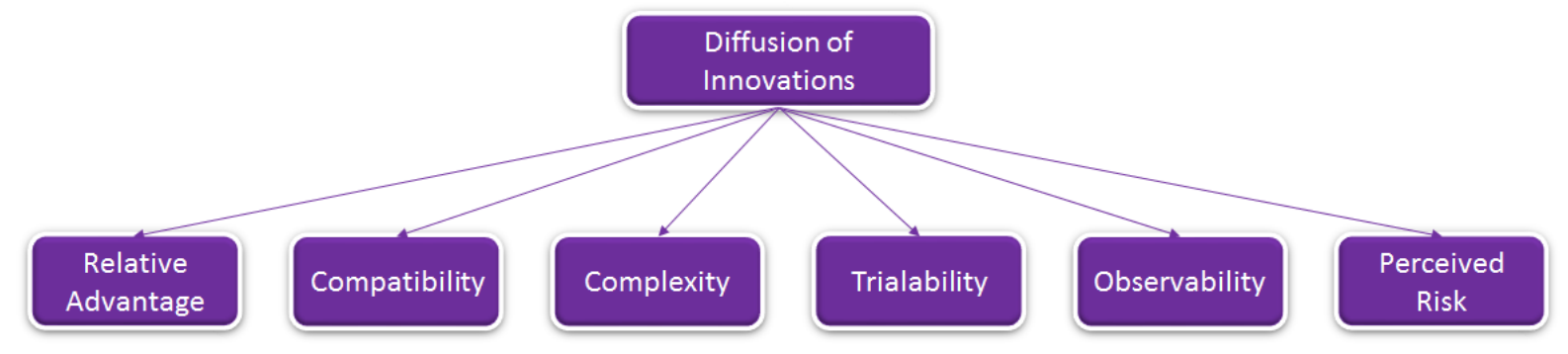

Source: Dwivedi (2005) 
Relative Advantage: The first construct, relative advantage, refers to the superiority or the added benefit that an innovation provides over the already existing product that supersedes it (Dwivedi, 2005; Claudy et al., 2010; Lichtenstein \& Williamson, 2006). This would affect the consumer's decision to adopt the product as it offers an additional benefit to the consumer (Chinman, Lucksted, Gresen, Davis, Losonczy, Sussner \& Martone, 2008). However, the superiority or added benefit of the innovation is subjective since it is based on the consumer's perception and not on factual evidence (Demoulin \& Zidda, 2009).

Compatibility: The second construct, compatibility, refers to how well the innovation fits into the existing consumer routines, values, experiences, beliefs, behaviours, and needs of the consumer whom it is intended to target (Claudy, 2011; Lichtenstein \& Williamson, 2006). Familiarity with the features or any other attributes of the innovation is likely to affect how compatible the innovation is with the consumer (Kleijnen et al., 2009).

Complexity: The third construct, complexity, is the scale of difficulty associated with understanding and using a new innovation (Demoulin \& Zidda, 2009). The more difficult an innovation is perceived to be in terms of understanding and use, the less likely it is that the innovation will be adopted by a consumer (Claudy, 2011; MacVaugh \& Schiavone, 2010).

Trialability: The fourth construct, trialability, refers to the opportunity given to experiment with a new, innovative product, with the idea that it will aid a potential customer in deciding whether or not to adopt the product (Claudy et al., 2010; Lichtenstein \& Williamson, 2006). Trials typically span over a limited amount of time before adoption takes place and are used as mechanisms to reduce the consumer's perceived risk of adopting the innovation (Chinman et al., 2008).

Observability: Fifthly, observability is the visibility rate of successfully using an innovation in front of other individuals within a specific social group, and how communicable the innovation is among that group (Kleijnen et al., 2009). When there is low visibility of successful use of an innovation, the rate of adoption slows (Lichtenstein \& Williamson, 2006).

Perceived Risk: The sixth construct, perceived risk, is the level of uncertainty surrounding an innovation and has been divided into five types of risk, namely physical, psychological, social, financial, and functional risk (Kleijnen et al., 2009). Consumers will search for information regarding the innovation's features that could possibly be beneficial in order to reduce the perceived level of risk associated with adopting an innovation (Dwivedi, 2005). However, certain consumers would rather purchase and pay a higher fee for a product that has familiarity and, therefore they experience less uncertainty (Talke, Saloma, Weiringa, \& Lutz, 2009). Based on previous research conducted, which is summarised in Table 1, it can be seen that overall, each of the six constructs aids in the understanding of the Diffusion of Innovations Model, each contributing uniquely towards relating adoption and behaviour to innovations, and explaining how this process occurs over a period of time, so defining the rate of adoption of an innovative product (Demoulin \& Zidda, 2009; Haghirian et al., 2008; Kumar et al., 2007).

Consumer Resistance: Today's consumer displays more dominance over the choice to consume and the ability to resist marketing efforts, such as ignoring or adapting even the most lustrous marketing campaigns: this defines the expression, consumer resistance (Abzakh et al., 2013; Moraes et al., 2008). Consumer resistance refers to consumers' efforts to reject a particular product or service, whether it is innovative in nature or not (Galvagno, 2010). Consumer resistance is a behaviour that is exhibited by consumers concerning a particular general motivation or group action and can include behaviours such as rejection, postponement, or opposition (Cova \& Dalli, 2008; Kleijnen et al., 2009).

Problem Investigated: The application of Dwivedi's (2005) Diffusion of Innovations Model has been examined and applied in several studies (Bartells \& Reinders, 2011; Chinman et al., 2008; Claudy, 2011; Demoulin \& Zidda, 2009; Haghirian et al., 2008; Kumar et al., 2007; Lichtenstein \& Williamson, 2006). Furthermore, the e-cigarette field has witnessed an expansion of knowledge through works that have explored different facets. For example, e-cigarette awareness (Cho, Shin \& Moon, 2011; Regan, Promoff, Dube \& Arrazola, 2013), e-cigarette users and behaviour (Bullen, McRobbie, Thornley, Glover, Lin \& Laugesen, 
2010; Dawkins, Turner, Hasna \& Soar, 2012), the side-effects of using e-cigarettes (Schripp et al., 2013; Vansickel, Cobb, Weaver \& Eissenberg, 2010), and e-cigarette diffusion (Bitton \& Bates, 2010). Despite a vast amount of literature in this field, a lack of research remains on e-cigarette resistance. Therefore, by means of a proposed conceptual model, the present article aims to fill the gap in literature by investigating the factors that affect consumer resistance to e-cigarette diffusion among students in Johannesburg. Figure 2 presents the conceptual model.

\section{Figure 2: Conceptual Model}

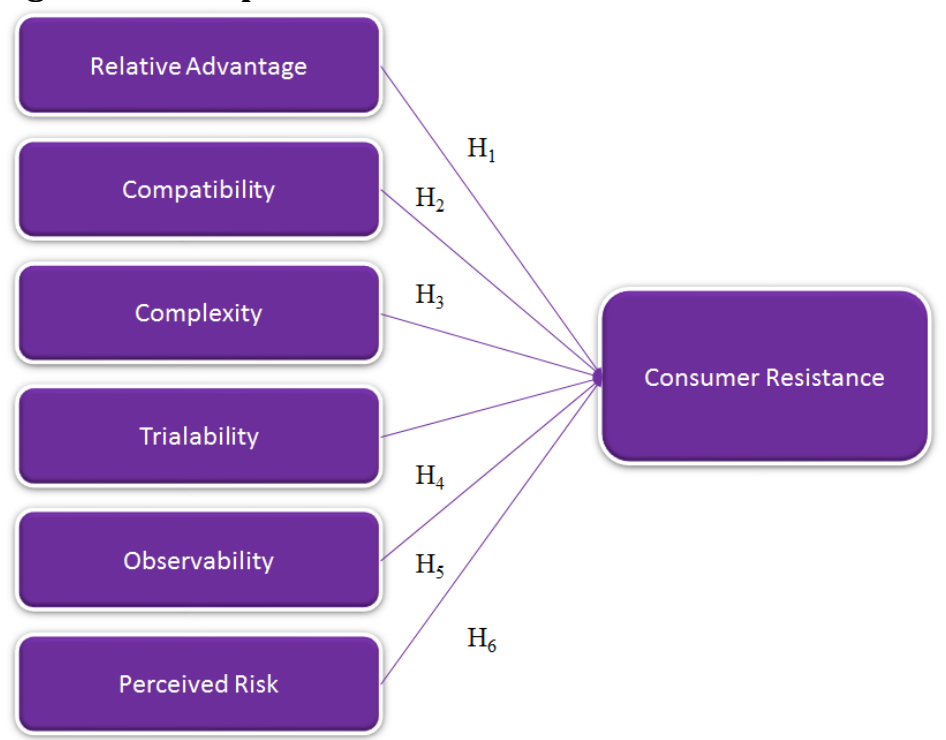

Source: Compiled by Researcher

The conceptual model (Figure 2) proposes that the independent variables are relative advantage, compatibility, complexity, trialability, observability, and perceived risk, with the dependent variable being consumer resistance. In other words, it is proposed that the aforementioned independent variables have a direct effect on consumer resistance. The following section discusses the hypotheses development.

\section{Hypotheses Development}

Relative Advantage and Consumer Resistance: The relationship between relative advantage and consumer resistance has been explored in prior literature with generally consistent findings: the higher the relative advantage of adopting a new product, the lower the level of consumer resistance. In a study conducted by Schwarz and Ernst (2008), findings revealed that consumers are more likely to associate with innovations that have a high relative advantage, in comparison with a lower, or nor relative advantage. This notion was supported in a number of related studies (Al-Jabri \& Sohail, 2012; Claudy, 2011; Lichtenstein \& Williamson, 2006). This article proposes that a negative relationship exists between relative advantage and consumer resistance.

$H_{1}$ : There is a negative relationship between relative advantage and consumer resistance.

Compatibility and Consumer Resistance: The second hypothesis, the relationship between compatibility and consumer resistance, has proved to be negative in previous studies. For example, Kleijnen et al. (2009) conducted a meta-analysis of resistance drivers and found that low compatibility leads to the postponement of innovation adoption, indicating consumer resistance. Furthermore, in a study by Claudy (2011) on consumer resistance toward green innovations, results reflect a negative relationship. In other words, the higher the level of compatibility with an innovation, the lower the level of consumer resistance. Therefore, the present study proposes that there is a negative relationship between compatibility and consumer resistance. $\mathrm{H}_{2}$ : There is a negative relationship between compatibility and consumer resistance. 
Complexity and Consumer Resistance: Derived from previous literature (Claudy et al., 2010; Korhonen \& Kaarela, 2011; MacVaugh \& Schiavone, 2010), the relationship between complexity and consumer resistance has been found to be positive. This means that the more complex a product innovation, the higher the possibility of consumer resistance. In Claudy's et al. (2010) study on green innovations, complexity is stated to be a major driver of resistance towards the adoption of green products. Furthermore, in Korhonen and Kaarela's (2011) study indicated that complexity is positively related to resistance in the industrial services industry. Similarly, MacVaugh and Schiavone's (2010) findings indicated that the more difficult an innovation is perceived to be in terms of understanding and usage, the less likely it is that the innovation will be adopted by the consumer. Thus, it is posited that there is a positive relationship between complexity and consumer resistance.

$H_{3}$ : There is a positive relationship between complexity and consumer resistance.

Trialability and Consumer Resistance: The fourth hypothesis proposes a negative relationship between trialability and consumer resistance. This proposition is supported by prior literature. For example, Demoulin and Zidda (2009) found that trialability decreases consumer resistance with the adoption of grocery retail loyalty cards. In a study by Claudy et al. (2010), findings revealed that trialability has a negative effect on consumer resistance. Furthermore, Schwarz and Ernst (2008) investigated water-saving devices and observed a positive relationship between trialability and adoption. Derived from the conceptions considered above, the present study proposes a negative relationship between trialability and consumer resistance.

$H_{4}$ : There is a negative relationship between trialability and consumer resistance

Observability and Consumer Resistance: The relationship between observability and consumer resistance has previously been explored in Fetscherin and Lattemann's (2008) research, which concluded that observability positively affects user intention and acceptance in Virtual Worlds. Observability can also be represented as a negatively related variable to consumer resistance because of the fact that teens are more open to the adoption of e-cigarettes once it has been observed in a favourable setting (for example family and friends using the product) (Mail \& Guardian, 2015). These results were supported in a study by Lichtenstein and Williamson (2006), in which the findings revealed that low visibility decreases the rate of adoption. This suggests that there is a negative relationship between observability and consumer resistance ofe-cigarettes $H_{5}$ : There is a negative relationship between observability and consumer resistance.

Perceived Risk and Consumer Resistance: The last hypothesis tests the relationship between perceived risk and consumer resistance. Most previous literature indicates a positive relationship between these two variables. For example, Abzakh et al. (2013) identified perceived risk as a factor that influences potential consumers' resistance towards the use of generic drugs. In a study conducted by Schwarz and Ernst (2008), findings revealed a significantly positive relationship between perceived risk and adoption intention. In other words, the higher the perceived risk in adopting a new product, the lower the possibility of adoption intention. Talke et al. (2009) supported these findings that a negative relationship exists between perceived risk and consumer resistance. It suggests that there is a positive relationship between perceived risk and consumer resistance.

$H_{6}$ : There is a positive relationship between perceived risk and consumer resistance.

Research Objectives: The primary objective of the present article is to investigate the influence of an innovation's characteristics (relative advantage, compatibility, complexity, trialability, observability and perceived risk) on consumer resistance of e-cigarettes among university students in Johannesburg.

\section{Methodology}

Research Philosophy: The research philosophy is expressed in terms of research design, typology and methodology. This study follows a non-experimental research design since there is no manipulation of the independent variable, there is only one sample with no control group, and there is no randomisation (Creswell, 2014; Mackey \& Gass, 2005; Murphy \& Davidshofer, 2005). This type of design was selected because it is easy to implement and it is cost and time efficient (Saunders et al, 2012). Because the study examines the relationship between variables, it follows a correlational typology (Heppner et al, 2008, Malhotra, 2010). Furthermore, using a quantitative methodology means that the research has followed a 
positivistic paradigm, which implies that the study followed a stable reality, investigated through a scientific method such as hypothesis testing and that the researcher remained objective throughout the study (Creswell, 2014; Mackey \& Gass, 2005).

Ethical Considerations: Confidentiality and anonymity were ensured by undergoing a rigorous procedure to obtain ethical clearance allowing for the continuation of the research. Furthermore, ethics was incorporated into the study by ensuring that each participant signed a letter of consent which informed them that their protection and welfare were considered, no deception was used in the study, and that they had the right to withdraw at any stage during the completion.

Sampling: The sample comprised of 400 students from the University of the Witwatersrand, both male and female between the ages of 18 and 25, classifying them as the youth market. University students were chosen as the sample since it has been concluded that this age group is renowned for initiating change, especially with novelty items, such as the e-cigarette (Sutfin et al., 2013; Trumbo \& Harper, 2013). By means of nonprobability convenience sampling, the respondents were randomly selected on campus and invited to complete the self-administered surveys. This type of sampling was chosen because it conforms to the objectives of the study and it is convenient and economical (Biaxter et al., 2010; Creswell, 2014).

Data Collection and Questionnaire Design: The data was gathered through the completion of a questionnaire targeted specifically at university students who smoke either tobacco cigarettes or the ecigarette or are non-smokers who may provide insight into consumer resistance. A questionnaire was chosen as the method of data-gathering because of its many advantages, namely that it can be administered to large numbers of people, it is time-efficient and cost-efficient, it provides anonymity, and it can yield valuable descriptive information about trends (Saunders et al., 2012). The questionnaires took approximately 10 to 15 minutes to complete with the constructs of the model operationalised through the use of preapproved marketing scales. Therefore, it is a multi-item scaled questionnaire, consisting of Likert-type scale questions, with the range of 1-strongly disagree to 7 -strongly agree.

Measurement Instrument Development: The measurement scales that were used for the present study were a modification of existing scales. Scales were selected based on their reliability and validity. For the first construct, relative advantage, a combination of Jung, Chan-Olmsted, Park \& Kim's (2011) and Forsythe, Liu, Shannon \& Gardner's (2006) scales were used. A combination of scales was adopted in order to more accurately assess the construct of interest. The second construct, compatibility, was measured using a modification of Jung's et al. (2011), and Wu and Wang's (2005) scales. Complexity was measured by an adaptation of Schreier, Oberhauser and Prügl's (2006) scale. Both trialability and observability were measured by modifications of Jung's et al (2011) scales. The sixth construct, perceived risk, was measured by adapting Abzakh's et al. (2013) scale. Lastly, consumer resistance was measured by a modified version of Abzakh et al. (2013) and Claudy's (2011) measurement scales.

\section{Findings}

Data analysis was completed using SPSS 22 for the descriptive statistics, while the model fit and path modelling was conducted using AMOS 22.

Descriptive Statistics: From the respondents, who were students from the University of the Witwatersrand, the majority of the them were female (59\%), between 18 and 25 years of age (99\%), had, at most, a high school level education (60\%), and were non-smokers (84\%).

Structural Equation Modelling: Structural equation modelling (SEM) is used for the data analysis of the present article. SEM is a commonly used statistical technique for testing theory by means of proposed hypotheses (Liao \& Hsieh, 2013). One of the major advantages of using SEM is that it tests relationships between observed and latent variables that constitute the conceptual model (Qureshi \& Kang, 2014). SEM was also chosen because it is used more as a confirmatory technique, by which validity of the model, based on theory, is established. Therefore, the technique confirms the validity and reliability of the preapproved scales, which is called confirmatory factor analysis (CFA) (Murphy \& Davidshofer, 2005). In this article, six 
hypotheses are proposed and tested by means of a conceptual model. The analysis will be conducted by means of a model fit assessment, correlation matrix, scale accuracy analysis and hypotheses testing.

Model Fit: Model fit assessment was conducted using the following indices: CMIN/DF (Chi-Square Index), CFI (Comparative Fit Index), GFI (Goodness-of-Fit Index), IFI (Incremental Fit Index), NFI (Normed Fit Index), TLI (Tucker Lewis Index), and RMSEA (Root Mean Square Error of Approximation). The results depicted an acceptable model fit with the chi-square ratio being well below the recommended threshold of 3 with a value of 1.658 (Chinomona, 2011), the CFI (0.970), GFI (0.916), IFI (0.970), NFI (0.928), and TLI (0.959) were all accepted at a value above 0.8 (Hooper, Coughlan \& Mullen, 2008). Similarly, the RMSEA was accepted at 0.041 as it meets the recommended threshold of less than 3 (Chinomona, 2011). The model fit results are presented in Table 2.

Table 2: Model Fit

\begin{tabular}{lll}
\hline Fit Measures & CFA & Structural \\
\hline CMIN/DF & 1.658 & 2.638 \\
CFI & 0.970 & 0.933 \\
GFI & 0.916 & 0.876 \\
IFI & 0.970 & 0.937 \\
NFI & 0.928 & 0.898 \\
TLI & 0.959 & 0.898 \\
RMSEA & 0.041 & 0.064 \\
\hline
\end{tabular}

*Note: CMIN/DF - Chi-Squared Index; CFI - Comparative Fit Index; GFI - Goodness-of-fit Index; IFI Incremental Fit Index; NFI - Normed Fit Index; TLI - Tucker Lewis Index; RMSEA - Root Mean Square Error of Approximation.

Derived from the above mentioned results, it is evident that the proposed conceptual model is satisfactory inpresenting the underlying empirical data structure of the present study. An overall acceptable model fit was achieved with indice values meeting the requirements for deducing such conclusions.

Inter-Construct Correlation Matrix: An inter-construct correlation matrix was conducted to confirm discriminant validity of the constructs underlying the present study by indicating the correlations between all conceivable combinations of the constructs. The inter-construct correlation matrix was also utilised to indicate whether or not factor analysis would be appropriate. To ensure validity, values below 1.0 were aimed for (Chinomona, Lin, Wang \& Cheng, 2010).As indicated in Table 3, the inter-correlation values were all below 1 of which the majority yielded weaker relationships. For example, perceived risk (PR) and relative advantage (RA) (0.003), complexity (CE) and compatibility (CA) (0.031), and trialability (TR) and complexity (CE) (0.108) indicated positive relationships exist. Negative correlations were identified between consumer resistance (COR) and a number of constructs such as relative advantage (RA) (-0.377), trialability (TR) ($0.144)$, and observability $(\mathrm{OB})(-0.275)$ indicated negative relationships exist between the constructs.

Table 3: Inter-Construct Correlation Matrix

\begin{tabular}{llllllll}
\hline Research Constructs & RA & CA & CE & TR & OB & PR & COR \\
\hline Relative Advantage & & & & & & & \\
(RA) & 1 & & & & & & \\
Compatibility (CA) & 0.307 & 1 & & & & & \\
Complexity (CE) & -0.044 & 0.031 & 1 & & & \\
Trialability (TR) & 0.301 & 0.421 & 0.108 & 1 & & \\
Observability (OB) & 0.233 & 0.445 & -0.047 & 0.478 & 1 & & \\
Perceived Risk (PR) & 0.003 & -0.228 & 0.249 & -0.038 & -0.170 & 1 \\
Consumer Resistance & & & & & & & \\
(COR) & -0.066 & -0.377 & 0.217 & -0.144 & -0.275 & 0.700 & 1 \\
\hline
\end{tabular}

*Note: RA - Relative Advantage; CA - Compatibility; CE - Complexity; TR - Trialability; OB - Observability; PR - Perceived Risk; COR - Consumer Resistance. 
Scale Accuracy Analysis: Table 4 presents the accuracy analysis statistics which combines the Cronbach's alpha coefficients, composite reliability, average variance extracted, highest shared variance, and factor loadings of each of the constructs. These values indicate the reliability of the overall study. As evident from the results, the majority of the item-to-total values are above 0.7, while Cronbach's alpha coefficients ( $\alpha$ ), and composite reliability (CR) indexes range from 0.721 to 0.896 , and 0.706 to 0.888 respectively. These values meet the estimate requirements suggested for scale reliability.

Table 4: Scale Accuracy Analysis

\begin{tabular}{|c|c|c|c|c|c|c|c|c|}
\hline \multicolumn{2}{|c|}{$\begin{array}{l}\text { Research } \\
\text { Construct }\end{array}$} & \multirow[t]{2}{*}{ Mean } & \multirow[t]{2}{*}{$\begin{array}{l}\text { Standard } \\
\text { Deviation }\end{array}$} & \multirow[t]{2}{*}{$\begin{array}{l}\text { Cronbach } \\
\text { Alpha }\end{array}$} & \multirow[t]{2}{*}{ CR } & \multirow[t]{2}{*}{ AVE } & \multirow[t]{2}{*}{$\begin{array}{l}\text { Highest } \\
\text { Shared } \\
\text { Variance }\end{array}$} & \multirow{2}{*}{$\begin{array}{l}\begin{array}{l}\text { Factor } \\
\text { Loadings }\end{array} \\
0.694\end{array}$} \\
\hline RA & RA2 & & & & & & & \\
\hline & RA3 & & & & & & & 0.849 \\
\hline & RA4 & 4.332 & 1.521 & 0.826 & 0.809 & 0.698 & 0.091 & 0.643 \\
\hline & RA5 & & & & & & & 0.674 \\
\hline \multirow[t]{5}{*}{ CA } & CA1 & & & & & & & 0.716 \\
\hline & CA2 & & & & & & & 0.615 \\
\hline & CA3 & 3.198 & 1.670 & 0.851 & 0.849 & 0.658 & 0.198 & 0.547 \\
\hline & CA4 & & & & & & & 0.887 \\
\hline & CA5 & & & & & & & 0.841 \\
\hline \multirow[t]{4}{*}{ CE } & CE1 & & & & & & & 0.534 \\
\hline & CE2 & 3719 & 1280 & 0835 & 0851 & 0711 & 0062 & 0.919 \\
\hline & CE3 & 3.11 & 1.200 & 0.003 & 0.031 & 0.711 & 0.002 & 0.863 \\
\hline & CE4 & & & & & & & 0.715 \\
\hline \multirow[t]{4}{*}{ TR } & TR1 & & & & & & & 0.675 \\
\hline & TR2 & 4.019 & 1.476 & 0.896 & 0858 & 0.786 & 0.228 & 0.731 \\
\hline & TR3 & 4.019 & & & & $0 . / 86$ & $0.2 \angle 8$ & 0.916 \\
\hline & TR4 & & & & & & & 0.941 \\
\hline \multirow[t]{2}{*}{ OB } & OB1 & 3483 & 1610 & 0721 & 0706 & 0676 & & 0.751 \\
\hline & OB3 & 3.483 & 1.619 & 0.121 & 0.106 & $0.6 / 6$ & $0.2 \angle 8$ & 0.726 \\
\hline \multirow[t]{9}{*}{ PR } & PR1 & & & & & & & 0.55 \\
\hline & PR3 & & & & & & & 0.629 \\
\hline & PR4 & & & & & & & 0.436 \\
\hline & PR5 & & & & & & & 0.521 \\
\hline & PR6 & 4.474 & 1.373 & 0.838 & 0.792 & 0.396 & 0.062 & 0.492 \\
\hline & PR11 & & & & & & & 0.578 \\
\hline & PR12 & & & & & & & 0.635 \\
\hline & PR14 & & & & & & & 0.461 \\
\hline & PR15 & & & & & & & 0.589 \\
\hline \multirow[t]{4}{*}{ COR } & COR1 & & & & & & & 0.830 \\
\hline & COR2 & & & & & & & 0.701 \\
\hline & COR3 & 4.645 & 1.688 & 0.895 & 0.888 & 0.666 & 0.490 & 0.828 \\
\hline & COR4 & & & & & & & 0.894 \\
\hline
\end{tabular}

As prevalent in Table 4, the average variance extracted (AVE) values were above 0.4 , with the majority approaching 0.5. Thus, indicates acceptable levels of scale reliability (Fraering\& Minor 2006). The AVE values for all the constructs were also greater than the highest shared variance which indicates discriminant validity is present, inferring that the results are valid.

Path Modelling and Hypothesis Testing: The results from the path modelling and hypotheses testing are presented in Table 5 followed by a discussion of these.

Discussion of the Results: From Table 5, the findings reveal that three of the six hypotheses (H1, H3 and H6) are supported at a 95\% confidence interval, with a p-value of less than 0.05 . Proving that relative advantage, complexity and perceived risk influence consumer resistance. A negative relationship was found between 
relative advantage and consumer resistance (H1), indicating that if the e-cigarette is perceived as having added benefits, consumers will be less resistant toward adopting it. The results from H3 revealed a positive relationship between complexity and consumer resistance. This implies that the more complex the e-cigarette is, the more likely that the consumer will not adopt it. Hypothesis 6 is also supported, providing evidence that there is a positive relationship between perceived risk and consumer resistance. This means that the higher the perceived risk of using an e-cigarette, the bigger the possibility of consumer resistance. Overall, the strongest relationship was between perceived risk and consumer resistance, with a regression estimate of 0.88.Therefore, the strongest predictor of e-cigarette resistance is perceived risk, followed by complexity (0.16) and relative advantage (0.03), respectively. On the other hand, $\mathrm{H} 2, \mathrm{H} 4$ and $\mathrm{H} 5$ are not supported at a 95\% confidence interval, inferring that compatibility, trialability and observability do not have an influence on consumer resistance $(p>0.05)$. These results provide the implications that regardless of how compatible consumers regard the e-cigarette to be with their lifestyle, their decision to resist will not be influenced by this variable. Similarly, if consumers can try the e-cigarette prior to purchase, their decision to resist will not be affected. Lastly, the observability of the e-cigarette will not influence consumer resistance.

\section{Table 5: Summary of Hypotheses Results}

\begin{tabular}{|c|c|c|c|c|}
\hline $\begin{array}{l}\text { Hypo- } \\
\text { thesis }\end{array}$ & Proposed hypothesised relationship & $\begin{array}{l}\text { Regression } \\
\text { Weights }\end{array}$ & $\begin{array}{l}\text { P- } \\
\text { value }\end{array}$ & Result \\
\hline H1 & $\begin{array}{l}\text { There is a negative relationship between relative } \\
\text { advantage and consumer resistance. }\end{array}$ & 0.03 & 0.489 & $\begin{array}{l}\text { Supported and } \\
\text { insignificant }\end{array}$ \\
\hline $\mathrm{H} 2$ & $\begin{array}{l}\text { There is a negative relationship between } \\
\text { compatibility and consumer resistance. }\end{array}$ & -0.31 & $* * *$ & $\begin{array}{l}\text { Unsupported } \\
\text { and } \\
\text { significant* }\end{array}$ \\
\hline H3 & $\begin{array}{l}\text { There is a positive relationship between complexity } \\
\text { and consumer resistance }\end{array}$ & 0.16 & 0.022 & $\begin{array}{l}\text { Supported and } \\
\text { significant* }\end{array}$ \\
\hline $\mathrm{H} 4$ & $\begin{array}{l}\text { There is a negative relationship between trialability } \\
\text { and consumer resistance }\end{array}$ & 0.00 & 0.978 & $\begin{array}{l}\text { Unsupported } \\
\text { and } \\
\text { insignificant }\end{array}$ \\
\hline H5 & $\begin{array}{l}\text { There is a negative relationship between } \\
\text { observability and consumer resistance. }\end{array}$ & -0.07 & 0.195 & $\begin{array}{l}\text { Unsupported } \\
\text { and } \\
\text { insignificant }\end{array}$ \\
\hline H6 & $\begin{array}{l}\text { There is a positive relationship between perceived } \\
\text { risk and consumer resistance. }\end{array}$ & 0.88 & $* * *$ & $\begin{array}{l}\text { Supported and } \\
\text { significant* }\end{array}$ \\
\hline
\end{tabular}

*Note: RA - Relative Advantage; CA - Compatibility; CE - Complexity; TR - Trialability; OB - Observability; PR - Perceived Risk; COR - Consumer Resistance.

Managerial Implications: The present study provides marketers of the e-cigarette with a clearer understanding of the factors that influence e-cigarette rejection. As a result, marketers are able to manage more successfully the diffusion process of e-cigarettes and, subsequently to improve the adoption rate. For example, it is crucial for e-cigarette marketers to concentrate their efforts on clearly communicating the relative advantage of the e-cigarette. Further, it is evident that respondents fail to understand how they will benefit from using such an innovation. Marketers should, as a result, formulate educational campaigns by emphasising that e-cigarettes are healthier, more cost-effective in the long run, and can be used anywhere and at any time since it does not release fumes that affect people in their vicinity. Furthermore, the results indicate that respondents perceive the e-cigarette to be a complicated product to use. Marketers can address this issue by promoting 'ease of use' and providing consumers with a step-by-step guide on how to use and service the e-cigarette. Manufacturers can also improve on the design of the product by increasing the lifespan of the filters, or by making the refilling of the e-liquid more convenient via an injector system that reduces the likelihood of spills. Another suggestion is to increase the longevity of the battery life so that consumers do not have to recharge the product as often, or have the inconvenience of the battery depleting in situations where it is difficult to recharge. Lastly, manufacturers can utilise economy packs in their sales strategies. An economy pack offers more than a so-called bulk item that comes with the offer of a discount. These economy packs are likely to work well with the use of larger e-liquid refills, such that the e-liquid would cut down on the inconvenience of having to visit an e-cigarette retailer or shop online for refills: with an economy pack, the offer of a discount for buying more products could incentivise sales and reduce the 
perceived complexity of the e-cigarette. Lastly, the results indicated that respondents associated the ecigarette with a perceived risk, of possible harm. This can be due to a lack of information available on the possible health effects of using an e-cigarette. Marketers should focus on educating consumers on the health benefits of using the e-cigarette in comparison to normal cigarettes. By showing the consumer that long-term use is in fact a healthier option with no unwanted long-term effects, the consumer's perceived risk will be reduced. This will lead to a decrease in consumer resistance.

\section{Conclusion, Limitations and Future Research}

In conclusion, an evaluation of the predictors of the Diffusion of Innovations Model in relation to consumer resistance among university students in Johannesburg was researched by means of a quantitative study. Through the analysis of the data collected, it was discovered that relative advantage, complexity and perceived risk positively influence consumer resistance of e-cigarettes. Marketers need to employ strategies that emphasise the advantage and simplicity of using the e-cigarette, and should also educate consumers on the health benefits of using the e-cigarette. Although this study makes a significant contribution to the theory and practice of the e-cigarette market, it is not without its limitations. Firstly, there is a risk of bias since the sample does not employ randomisation, and therefore a lack of equal opportunity might have yielded systematic errors in the sample group. Future research should employ a sampling technique that can incorporate randomisation effectively, and if possible, the manipulation of the independent variable. By including these two characteristics, causality can be observed, which provides for a stronger research result. A second limitation is the demographic profile of the respondents, being only students from the University of the Witwatersrand. Future studies can focus on Generation Y individuals from other universities nationwide, or other segments of the market. This will ensure a valid representation of the research results.

\section{References}

Abzakh, A. A., Ling, K. C. \& Alkilani, K. (2013). The Impact of Perceived Risks on the Consumer Resistance towards Generic Drugs in the Malaysia Pharmaceutical Industry. International Journal of Business and Management, 8(3), 42-50.

Al-Jabir, I. M. \& Sohail, M. S. (2012). Mobile banking adoption: Application of diffusion of innovation theory. Journal of Electronic Commerce Research, 13(4), 1-13.

Arts, J. W. C., Frambach, R. T. \& Bijmolt, T. H. A. (2011). Generalizations on consumer innovation adoption: A meta-analysis on drivers of intention and behaviour. International Journal of Research in Marketing, 28(2), 1-40.

Barbeau, A. M., Burda, J. \& Siegel, M. (2013). Perceived efficacy of e-cigarettes versus nicotine replacement therapy among successful e-cigarette users: a qualitative approach. Addiction Science and Clinical Practice, 8(5), 1-7.

Bartels, J. \& Reinders, M. J. (2011). Consumer innovativeness and its correlates: A propositional inventory for future research. Journal of Business Research, 64, 601-609.

Biaxter, L., Hughes, C. \& Tight, M. (2010). How to Research (4th Ed.). New York: McGraw-Hill Companies.

Borland, R. (2011). Electronic Cigarettes as a Method of Tobacco Control. Britain Medical Journal. doi: 1136/bmj.d6269.

Bullen, C., McRobbie, H., Thornley, S., Glover, M., Lin, R. \& Laugesen, M. (2010). Effect of an electronic nicotine delivery device (e cigarette) on desire to smoke and withdrawal, user preferences and nicotine delivery: randomised cross-over trial. Tobacco Control, 19(2), 98-103.

Caponnetto, P., Polosa, R., Auditore, R., Russo, C. \& Campagna, D. (2011). Smoking Cessation with E-Cigarettes among Smokers with a Documented History of Depression and Recurring Relapses. International Journal of Clinical Medicine, 2, 281-284. doi: 10.4236/ijcm.2011.23046.

Chinman, M., Lucksted, A., Gresen, R., Davis, M., Losonczy, M., Sussner, B. \& Martone, L. (2008). Early Experiences of Employing Consumer-Providers in the VA. Psychiatric Services, 59(11), 1315-1322.

Chinomona, E. (2011). Non-mediated channel powers and relationship quality: a case of SME's in Zimbabwe channels of distribution. Cape Town: SAIMS. $\left(27^{\text {th }}\right.$ conference of the Southern Institute for Management Scientists: 30-1 Sep.) 
Chinomona, R., Lin, J. Y. C., Wang, M. C. H. \& Cheng, J. M. S. (2010). Soft power and desirable relationship outcomes: the case of Zimbabwean distribution channels. Journal of African Business11(2), 182-200.

Cho, J. H., Shin, E. \& Moon, S. (2011). Electronic-Cigarette Smoking Experience among Adolescents. Journal of Adolescent Health, 49, 542-546.

Claudy, M. (2011). An Empirical Investigation of Consumer Resistance to Green Product Innovation. Doctoral Thesis. Dublin Institute of Technology.

Claudy, M., O’Driscoll, A., Garcia, R. \& Mullen, M. (2010). Consumer Resistance to green Innovations: Developing a New Scale and an Underlying Framework. 35 th Macromarketing Conference: Wyoming.

Cova, B. \& Dalli, D. (2008). From communal resistance to tribal value creation. 1st International Conference on Consumption and Consumer Resistance, Paris, 28 November.

Creswell, J. W. (2014). Research Design (4th Ed.). London: sage Publications Ltd.

Dawkins, L., Turner, J., Hasna, S. \& Soar, K. (2012). The electronic cigarette: affects on desire to smoke, withdrawal symptoms and cognition. Addictive Behaviours, DOI: 10.1016/j.addbeh.2012.03.004.

Demoulin, N. T. M. \& Zidda, P. (2009). Drivers of Customers' Adoption and Adoption Timing of a New Loyalty Card in the Grocery Retail Market. Journal of Retailing, 85(3), 391-405.

Denegri-Knott, J., Zwick, D. \& Schroeder, J. E. (2006). Mapping consumer power: an integrative framework for marketing and consumer research. European Journal of Marketing, 40(9/10), p950-971.

Dwivedi, Y. K. (2005). Adoption, Usage and Impact of Broadband: UK Households. n.a.

Etter, J. (2010). Electronic cigarettes: a survey of users. BMC Public Health, 10(231), 1-7.

Fetscherin, M. \& Lattemann, C. (2008). User Acceptance of virtual Worlds. Journal of Electronic Commerce Research, 9(3), 231-242.

Forsythe, S., Liu, C., Shannon, D. \& Gardner L. C. (2006). Development of a scale to measure the perceived benefits and risks of online shopping. Journal of Interactive Marketing, 20(2), 55-75.

Fraering, M. \& Minor, M. S. (2006). Sense of community: an exploratory article of US consumers of financial services. International Journal of Bank Marketing, 24(5), 284-306.

Galvango, M. (2010). The intellectual structure of the anti-consumption and consumer resistance field. European Journal of Marketing, 46(11/12), 1688-1701.

Ghauri, P. \& Grønhaug, K. (2010). Research Methods in Business Studies (4 ${ }^{\text {th }}$ Ed.). New Jersey: Pearson Education Ltd.

Goniewicz, M. L., Knysak, J., Gawron, M., Kosmider, L., Sobczak, A., Kurek, J., Prokopowicz, A., Jablonska-Czapla, M., Rosik-Dulewska, C., Havel, C., Jacob, P. \&Benowitz, N. (2013). Levels of Selected Carcinogens and Toxicants in Vapour from Electronic Cigarettes. Tobacco Control. doi: 10.1136/tobaccocontrol2012050859.

Goniewicz, M. L., Lingas, O. L. \& Hajek, P. (2013). Patterns of electronic cigarette use and user beliefs about their safety and benefits: An Internet survey. Drug and Alcohol Review, 32, 133-140. doi: 10.1111/j.1465-3362.2012.00512.x.

Gourville, J. T. (2006). Eager Sellers and Stony Buyers: Understanding the Psychology of New-Product Adoption. Harvard Business Review, pp.99-106.

Haghirian, P., Madlberger, M. \& Inoue, A. (2008). Mobile Advertising in Different Stages of Development: A Cross-Country Comparison of Consumer Attitudes.41 ${ }^{\text {st }}$ Hawaii International Conference on System Sciences.

Health New Zealand Ltd. (2009). Ruyan $® E$-cigarette Bench-top tests. Poster 5-11, Society for Research on Nicotine and Tobacco. Christchurch, New Zealand. Laugesen, M.

Heavner, K., Dunworth, J., Bergen, P., Nissen, C. \& Phillips, C. V. (2009). Electronic cigarettes (e-cigarettes) as potential tobacco harm reduction products: Results of an online survey of e-cigarette users, 1-14.

Heppner, P. P., Kivlighan, D. M. \& Wampold, B. E. (2008). Research Design in Counselling (3 ${ }^{\text {rd }}$ Ed.). Belmont: Thomson Higher Education.

Jung, J., Chan-Olmsted, S., Park, B. \& Kim, Y. (2012). Factors affecting e-book reader awareness, interest, and intention to use. New Media Society, 14(2), 204-224.

Kleijnen, M., Lee, N. \& Wetzels, M. (2009). An exploration of consumer resistance to innovation and its antecedents. Journal of Economic Psychology, 30(3), 344-357.

Korhonen, H. \& Kaarela, I. (2011). Corporate customers' resistance to industrial service innovations. International Journal of Innovation Management, 15(3), 479-503.

Kumar, V., Kukerji, B., Butt, I. \& Persaud, A. (2007). Factors for Successful e-Government Adoption: a Conceptual Framework. The Electronic Journal of e-Government, 5(1), 63-76. 
Lee, S., Kimm, H., Yun, J. E. \& Jee, S. H. (2011). Public health Challenges of Electronic Cigarettes in South Korea. Journal of Preventative Medicine and Public Health, 44(6), 235-241.

Liao, C. H. \& Hsieh, I. Y. (2013). Determinants of consumer's willingness to purchase gray-market smartphones. Journal of Business Ethics, 114(3), 409-424.

Lichtenstein, S. \& Williamson, K. (2006). Understanding Consumer Adoption of Internet Banking: An Interpretive Study in the Australian Study in the Australian Banking Context. Journal of Electronic Commerce Research, 7(2), 50-67.

MacVaugh, J. \& Schiavone, F. (2010). Limits to the diffusion of innovation: A literature review and integrative model. European Journal of Innovation Management, 13(2), 197-221.

Mail \& Guardian. (2014). E-cigs fall through cracks of law. Matthew Burbridge. Retrieved from http://mg.co.za/article/2014-05-23-e-cigs-fall-through-cracks-of-law.

Malhotra, N. K. (2010). Marketing Research: An Applied Orientation (6 ${ }^{\text {th }}$ Ed.). New Jersey: Pearson Education Ltd.

Moraes, C., Szmigin, I. \& Carrigan, M. (2008). Consumer resistance, coherent inconsistencies, and new consumption communities. In: 1st International Conference on Consumption and Consumer Resistance, 28 November 2008, IRG-University Parist 12.

Odum, L. E., O’Dell, K. A. \& Schepers, J. S. (2012). Electronic Cigarettes: Do They Have a Role in Smoking Cessation? Journal of Pharmacy Practice, 25(6), 611-614.

Peters Jr, R. J., Meshack, A., Lin, M., Hill, M. \& Abughosh, S. (2013). The Social Norms and Beliefs of Teenage Male Electronic Cigarette Use. Journal of Ethnicity inSubstance Abuse, 12(4), 300-307. doi: 10.1080/15332640.2013.819310.

Polosa, R., Caponnetto, P., Morjaria, J. B., Papale, G., Campagna, D. \& Russo, C. (2011). Effect of an electronic nicotine delivery device (e-cigarette) on smoking reduction and cessation: A prospective 6-month pilot study. BioMed Central Public Health, 11(786), 1-12.

Qureshi, S. M. \& Kang, C. (2014). Analysing the organisational factors of project complexity using structural equation modelling. International Journal of Project Management, 33(1), 165-176.

Schreier, M., Oberhauser, S. \& Prügl, R. H. (2007). Lead users and the adoption and diffusion of new products: Insights from two extreme sports communities. Marketing Letters, 18(1-2), 15-30.

Schripp, T., Markewitz, D., Udhe, E. \& Salthammer, T. (2013). Does e-cigarette consumption cause passive vaping? John Wiley and Sons $A / H, 23,25-31$. DOI: 10.1111/j.1600-0668.2012.00792.x.

Schwarz, N. \& Ernst, A. (2008). Die Adoption von Technischen Umweltinnovationen: das Beispiel Trinkwasser. Umwelt psychologie, 22(1), 28-48.

Siegel, M. B., Tanwar, K. L. \& Wood, K. S. (2011). Electronic Cigarettes as a Smoking-Cessation Tool: Results from an Online Survey. American Journal of Preventative Medicine. doi: 10.1016/j.amepre.2010.12.006.

Sutfin, E. L., McCoy, T. P., Morell, H. E. R., Hoeppner, B. B. \& Wolfson, M. (2013). Electronic cigarette use among college students. Drug and Alcohol Dependence, 131, 214-221.

Talke, K., Saloma, S., Wieringa, E. \& Lutz, A. (2009). What about Design Newness? Investigating the Relevance of a Neglected Dimension of Product Innovativeness.

Trtchounian, A., Williams, M. \& Talbot, P. (2010). Conventional and electronic cigarettes (e-cigarettes) have different smoking characteristics. Nicotine and Tobacco Research, 12(9), 905-912.

Trumbo, C. W. \& Harper, R. (2013). Use and Perception of Electronic Cigarettes among College Students. Journal of American College Health, 61(3), 149-155. doi: 10.1080/07448481.2013.776052.

World Health Organisation. (2015). Tobacco. Fact Sheet No.339. Retrieved from http://www.who.int/mediacentre/factsheets/fs339/en/.

Wu, J. \& Wang, S. (2005). What drives mobile commerce? An empirical evaluation of the revised technology acceptance model. Information and Management, 42, 719-729. 